\title{
EFFECT OF ROBO SAND ON STRENGTH CHARACTERISTIC OF RECYCLED AGGREGATE CONCRETE
}

\author{
A.Anbarasan ${ }^{1}$, M.Venkatesan ${ }^{2}$ \\ ${ }^{1}$ M.Tech Student, Department of Civil Engineering, Prist University, Kumbakonam Campus, Tamilnadu, India \\ ${ }^{2}$ Asst. Professor, Department of Civil Engineering, Prist University, Kumbakonam Campus, Tamilnadu, India
}

\begin{abstract}
With increased depletion of natural construction materials, alternative means must be sought for substitution of the same. Excessive energy consumption in the production of construction materials, environmental setbacks and debris disposal are some of the other burning issues fuelling the need for reuse of the raw materials. With the need of natural sand, there is an urgent need for a product that matches the properties of natural sand in concrete. Construction-Demolition waste and ROBO Sand are some of the upcoming resources which enables effective replacement of the materials of mineral origin. In the present work, natural coarse aggregate was replaced with recycled coarse aggregate and river sand was replaced with ROBO Sand in different percentages in plain cement concrete. Different strength test were conducted with combination of ROBO Sand and recycled aggregate to study the effect of these two materials on strength Concrete with a characteristic compressive strength of $30 \mathrm{~N} / \mathrm{mm}^{2}$ (M30 grade), was used for our study. In total, 16 sets of 6 cubes each were cast and tested.
\end{abstract}

Keywords: ROBO Sand, recycled aggregate

\section{INTRODUCTION}

Concrete is a major building material which is used in construction throughout the globe. It is extremely good and is used for all types of structures. Due to rapid growth in construction sector, the extreme usage of concrete is rapidly increasing every year. This results in huge extraction of natural aggregates, which occupy 65 to $80 \%$ of the total volume of concrete. Out of the total composition of concrete, fine aggregate consumes 20 to $30 \%$ of volume. With a few local exceptions, it is expected ROBO Sand to be a global practice. Developing countries face lot of problems regarding exploitation of natural resources. Now a days the availability of natural sand is a constraint due to the immense growth in new designs old structures are demolished and the waste management is a problem, to overcome these problems some innovative way of recycling of waste should be done.

Current levels of demolition waste at UK construction sites are in the region of $70 \mathrm{Mt}$ per annum [1]. Of this only $10 \%$ finds use as aggregate, but mainly in road construction [2], where traditionally low grade aggregates are used. The remaining items are disposed as landfill. This low level of use clearly has economic and environmental implications and given the potential benefits associated with the material, dumping is no longer considered sustainable

\subsection{Objectives}

To study effect of ROBO Sand on compressive strength,tensile strength of recycled aggregate concrete and natural aggregate concrete. To study the cost aspects and arrive an optimum combination

\subsection{Research Study}

In our study, for each composition, four combinations each was tested. For 0\% Recycled coarse aggregate (RCA), 0\%, $30 \%, 50 \%$ and $100 \%$ Robo sand (RS)was added. Likewise for $30 \%, 50 \%$ and $100 \%$ RCA, RS is mixed as $0 \%$, $30 \%, 50 \%$ and $100 \%$. Totally $16 \mathrm{mix}$ proportions were tested. Strength test in terms of compression and tensile stress. Concrete mix of M30 is used for our study.

\section{MATERIAL PROPERTIES \& MIX DESIGN}

\subsection{Cement}

The cement used for the investigation was Ordinary Portland Cement with 53 grade. The specific gravity of cement was found out by density bottle method and the corresponding value is 3.15

\subsection{Coarse Aggregate}

Crushed aggregate available from local sources has been used. To obtain a reasonably good grading, aggregate passing through $20 \mathrm{~mm}$ IS sieve and retained on $16 \mathrm{~mm}$ IS sieve was used. The properties of coarse aggregate such as specific gravity and fineness modulus are found out as per Indian Standard guidelines. The specific gravity of coarse aggregate is 2.70 .

\subsection{Fine Aggregate}

Locally available river sand of size less than $4.75 \mathrm{~mm}$ was used. The specific gravity of fine aggregate is 2.65 , fineness modulus was found to be 2.7 as per IS $383: 1970$.

\subsection{ROBO Sand and Recycled Coarse Aggregate}

ROBO Sand are crusher dust which are collected from local 
quary and aggregate from demolished building are used as recycled coarse aggregate.Table 1 shows the Specific gravity of RS and RCA.

Table 1 Properties of Aggregates

\begin{tabular}{|l|l|}
\hline Aggregate & Specific gravity \\
\hline $\begin{array}{l}\text { Recycled coarse } \\
\text { aggregate (RCA) }\end{array}$ & 2.65 \\
\hline Robo sand (RS) & 2.29 \\
\hline
\end{tabular}

\subsection{Mix Design}

\begin{tabular}{|c|c|c|}
\hline Property & \multicolumn{2}{|l|}{ Value } \\
\hline $\begin{array}{l}\text { Required Characteristic } \\
\text { compressive strength }\end{array}$ & \multicolumn{2}{|l|}{$30 \mathrm{MPa}$} \\
\hline Maximum size of aggregate & \multicolumn{2}{|l|}{$20 \mathrm{~mm}$} \\
\hline Water Cement ratio & \multicolumn{2}{|l|}{0.4} \\
\hline Degree of workability & \multicolumn{2}{|l|}{0.90} \\
\hline Degree of quality control & \multicolumn{2}{|l|}{ Good } \\
\hline Type of exposure & \multicolumn{2}{|l|}{ Moderate } \\
\hline Mix Ratio & Weight & Ratio \\
\hline Water & 191 lit & 0.40 \\
\hline Cement & $478 \mathrm{~kg}$ & 1.00 \\
\hline Fine Aggregate & $519 \mathrm{~kg}$ & 1.01 \\
\hline Coarse Aggregate & $1179 \mathrm{~kg}$ & 2.48 \\
\hline
\end{tabular}

\section{TESTING OF SPECIMEN}

\subsection{Cube Compressive Strength}

Cubes of size $150 \mathrm{~mm} \times 150 \mathrm{~mm}$ were cast and the strength development was monitored for the ages of 7 and 28 days for compression using digital compression testing machine of $3000 \mathrm{kN}$ capacity. This paper presents the results of experimental investigations on concrete made with different percentages of recycled coarse aggregate and ROBO Sand. Specimens were designated. In all the four sets, natural sand and coarse aggregate was replaced in increasing percentages of $0,30,50 \& 100$. The first set had no replacement of aggregate while the last set had $100 \%$ replacement of natural aggregate with recycled coarse aggregate. The second and third sets had 30 and 50\% aggregate replacements respectively. Totally 96 cubes were tested, for $7^{\text {th }}$ and $28^{\text {th }}$ day test with 3 cube per combination.

\subsection{Split Tensile Strength Test}

For split tensile strength of concrete, $150 \mathrm{~mm} \times 300 \mathrm{~mm}$ cylinders were cast and cured for 7 and 28 days in water.

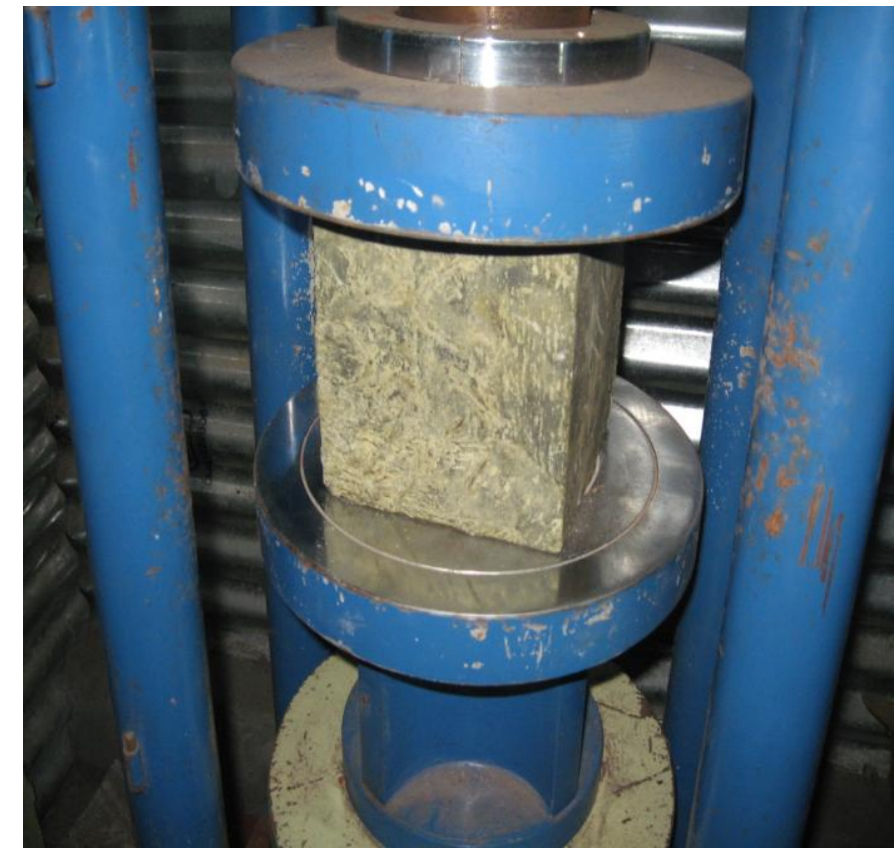

Chart 1- Compressive test

The test consists of applying compressive line loads along the opposite generators of a concrete cylinder placed with its axis horizontal between the platens. Due to the applied line loading a fairly uniform tensile stress is induced over nearly two - third of the loaded diameter as obtained from an elastic analysis. The magnitude of this tensile stress is given by $2 \mathrm{P} / \pi \mathrm{DL}=0.637 \mathrm{P} / \mathrm{DL}$.

\section{RESULTS AND DISCUSSION}

\subsection{Cube Compressive Strength}

Table 2- Compressive strength in N/mm $\mathrm{m}^{2}$

\begin{tabular}{|l|l|l|l|}
\hline MIX & $\begin{array}{l}\text { RCA- } \\
\text { ROBO } \\
\text { SAND\% }\end{array}$ & $\mathbf{7}^{\text {th }}$ Day & $\begin{array}{l}\mathbf{2 8}^{\text {th }} \\
\text { DAY }\end{array}$ \\
\hline Controlled & $0-0$ & 25.11 & 36.19 \\
\hline 1 & $0-30$ & 23.24 & 33.54 \\
\hline 2 & $0-50$ & 23.18 & 33 \\
\hline 3 & $0-100$ & 23.30 & 33.21 \\
\hline 4 & $30-0$ & 22.52 & 32.96 \\
\hline 5 & $30-30$ & 22.15 & 33.78 \\
\hline 6 & $30-50$ & 24.90 & 36.23 \\
\hline 7 & $30-100$ & 24.67 & 36.25 \\
\hline 8 & $50-0$ & 19.88 & 33.4 \\
\hline 9 & $50-30$ & 19.81 & 33.51 \\
\hline 10 & $50-50$ & 19.78 & 33.4 \\
\hline 11 & $50-100$ & 18.66 & 33.28 \\
\hline 12 & $100-0$ & 18.10 & 33.1 \\
\hline 13 & $100-30$ & 18.89 & 29.96 \\
\hline 14 & $100-50$ & 17.66 & 29.44 \\
\hline 15 & $100-100$ & 17.05 & 29.1 \\
\hline
\end{tabular}


The results on compressive strength of control concrete (0-0 combination) and concrete with different percentages of ROBO Sand are shown in table 2. Graphs plotted between the mix and compression strength, to identify the maximum compression strength value in $7^{\text {th }}$ and $28^{\text {th }}$ day. It can be seen from the results that, control concrete strength is 36.19 N/mm2 and RCA And ROBO Sand combination for 30-100 was found to be good when compared to other combinations at the age of 28 days.

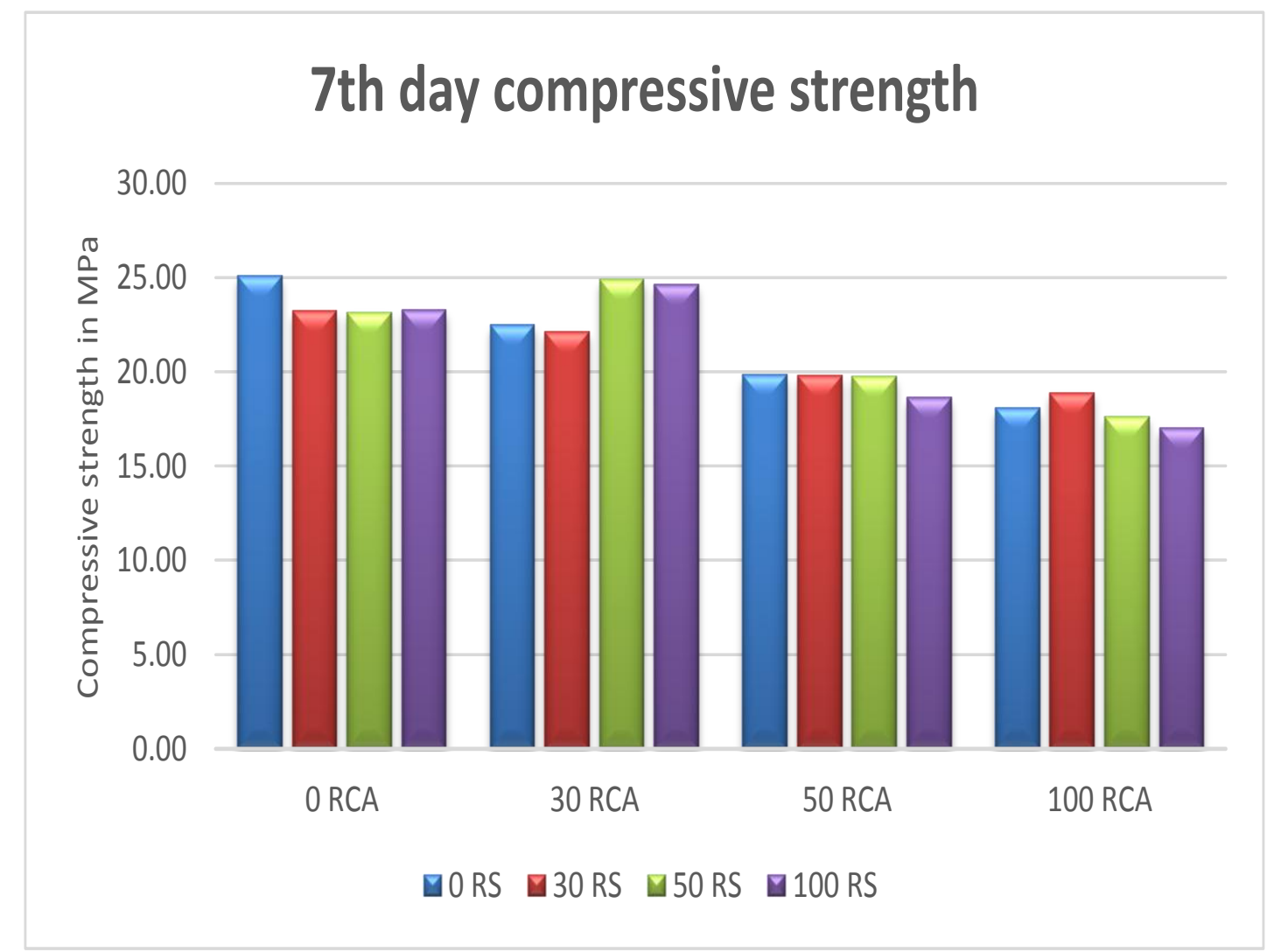

Chart 1 - 7th day compressive strength of the mixes

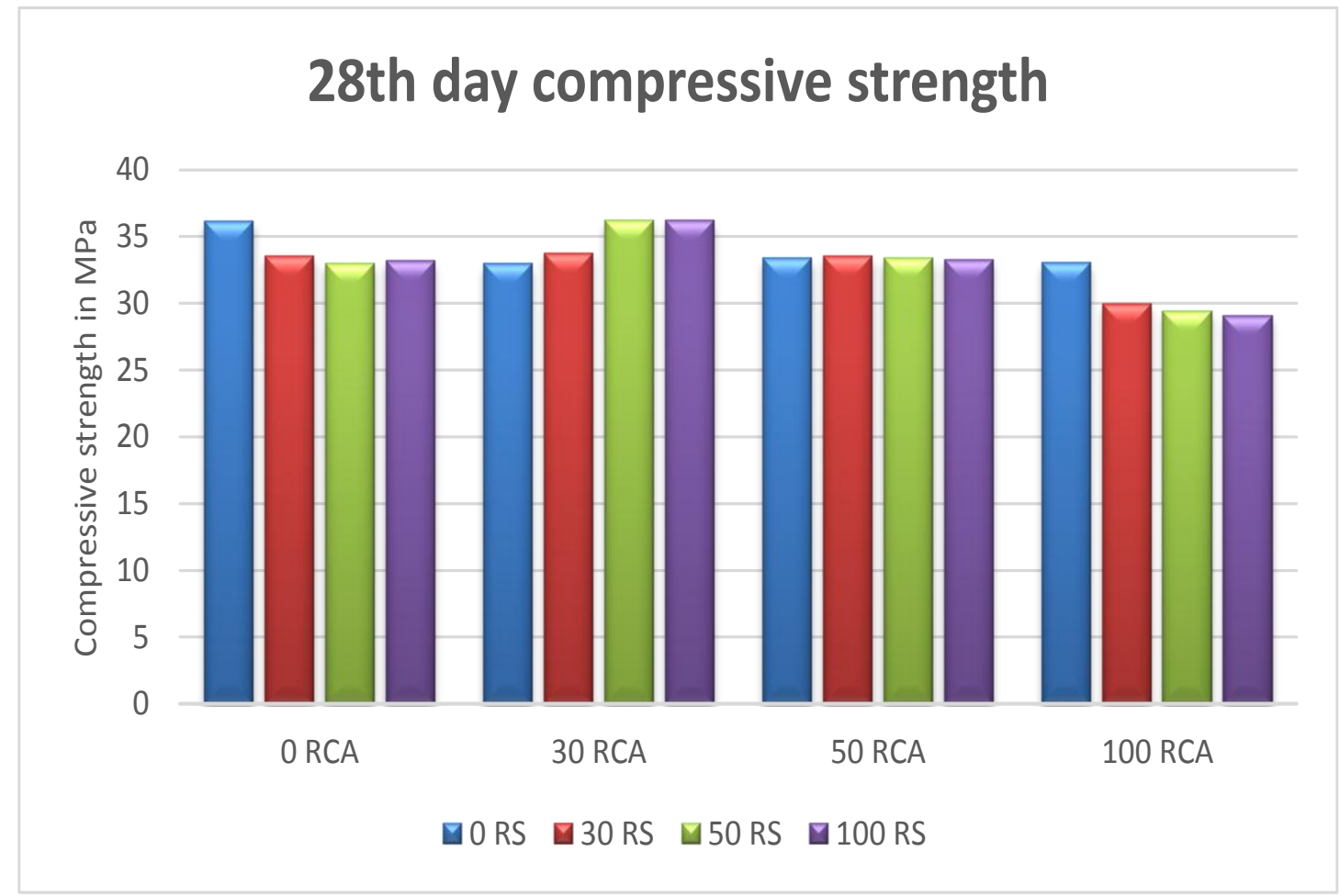

Chart 2 - 28th day compressive strength of the mixes 
All the different combinations shows better strength. In 7 days and 28days curing 30\% RCA and both 50\% and $100 \%$ ROBO (Mix 5 \& 6) Sand gives more strength when compared to other combinations. When RCA percentage increased, the results are seen decrease in strength. Therefore it can be said that, when 30\%RCA and 100\% RS is used, the strength of the concrete was similar to control concrete. Percentage increase of strength of mix 5and 6 is $0.11 \%$ and $0.16 \%$ respectively. It will pave the way to minimize the use of natural sand and natural aggregate and encourage the use of waste materials like ROBO SAND and RCA there by reducing disposal problem. It is also to be noted that, in the above case there will be considerable reduction in cost of construction, which in turn encourages the use of RCA in solving environmental problem The intermediate results depicting the various combinations of ROBO SAND+RCA can be used according to the design strength required considering the economical aspects.

\subsection{Split Tensile Strength Test}

Split tensile strength for all the mixes are tabulated in table 3. $7^{\text {th }}$ day and $28^{\text {th }}$ day tests were made for the mixes. Tensile stress variation for various mixes with respect to controlled concrete is noted in chart 3 .
Table 3- Tensile strength in N/mm ${ }^{2}$

\begin{tabular}{|l|l|l|l|}
\hline MIX & $\begin{array}{l}\text { RCA- } \\
\text { ROBO } \\
\text { SAND\% }\end{array}$ & ${7^{\text {th }}}^{\text {Day }}$ & $\mathbf{2 8}^{\text {th }}$ DAY \\
\hline Controlled & $0-0$ & 3.28 & 4.22 \\
\hline 1 & $0-30$ & 3.18 & 4.15 \\
\hline 2 & $0-50$ & 3.18 & 4.12 \\
\hline 3 & $0-100$ & 3.19 & 4.13 \\
\hline 4 & $30-0$ & 3.20 & 4.13 \\
\hline 5 & $30-30$ & 3.06 & 4.09 \\
\hline 6 & $30-50$ & 3.48 & 4.22 \\
\hline 7 & $30-100$ & 3.36 & 4.23 \\
\hline 8 & $50-0$ & 3.32 & 3.82 \\
\hline 9 & $50-30$ & 3.30 & 3.79 \\
\hline 10 & $50-50$ & 3.30 & 3.78 \\
\hline 11 & $50-100$ & 3.29 & 3.92 \\
\hline 12 & $100-0$ & 3.25 & 3.91 \\
\hline 13 & $100-30$ & 3.24 & 3.84 \\
\hline 14 & $100-50$ & 3.17 & 3.91 \\
\hline 15 & $100-100$ & 3.08 & 3.79 \\
\hline
\end{tabular}

\section{8th day Tensile strength}

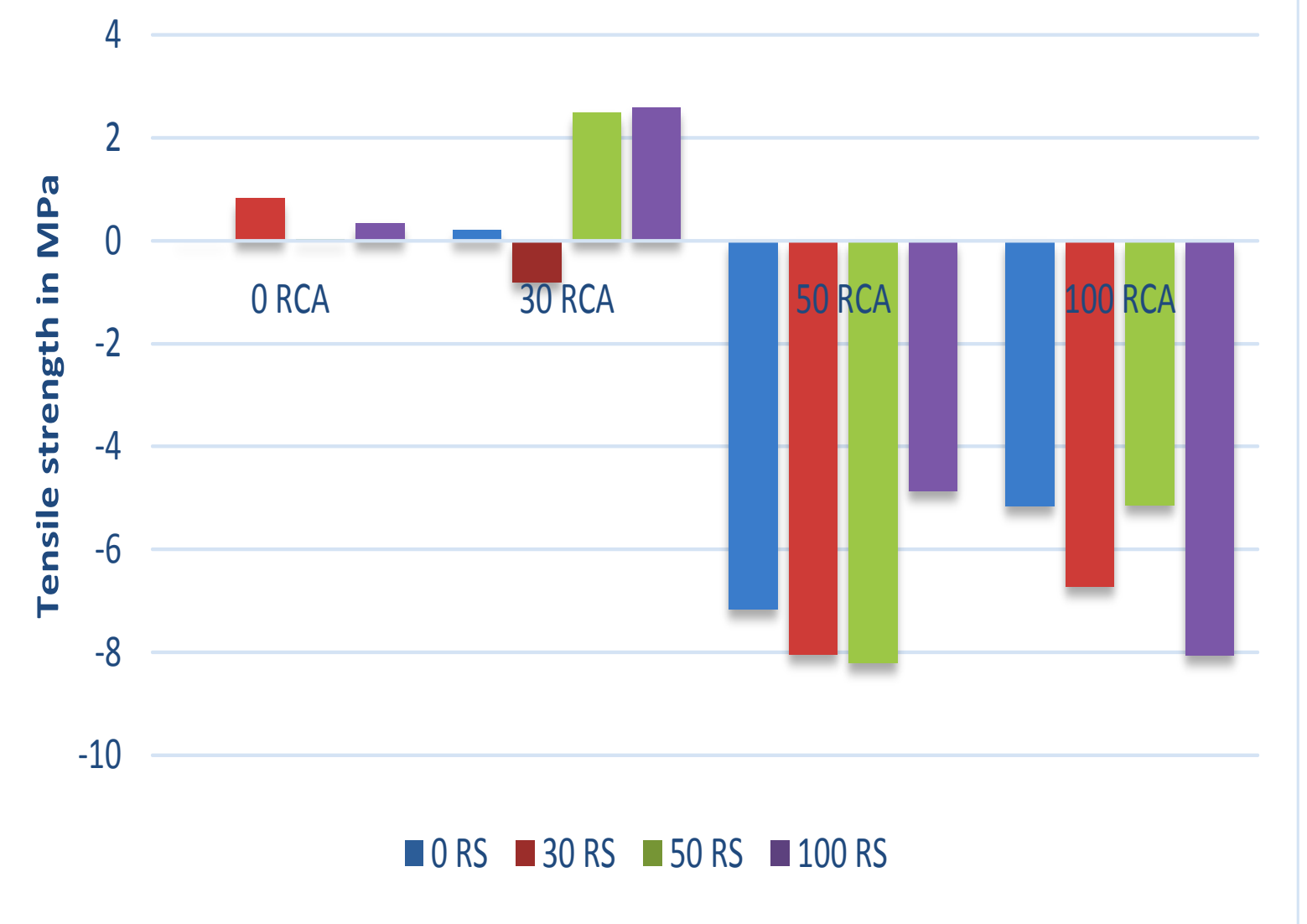

Chart 3- Percentage Variation in tensile strength 
It is seen from the chart 3, that there is percentage increase in tensile strength when the RCA is added upto $30 \%$. Above which, gives less strength than the controlled concrete. Maximum of $8 \%$ strength decrement is seen in mixes with RCA added more than $30 \%$. While seeing the increment in tensile stress, the mix 5 ( 50\% RS and 30\%RCA) and mix 6 ( $100 \%$ RS and 30\% RCA) shows $2.48 \%$ and $2.56 \%$ respectively. Though tensile strength is not an important factor in concrete, it is essential to know the performance of concrete with this new materials. Therefore these tests were made and results are discussed.

\section{CONCLUSION}

From the detailed experimental investigations carried out for different combinations of RCA with different percentages of ROBO SAND, following conclusions are arrived:

1. Strength aspect of RCA and ROBO Sand based concrete for $30-100 \%$ has shown good results both for 7 days and 28 days curing..

2. Cost aspect- to achieve reasonable strength with reduced cost comes with the same combination of $30 \%$ RCA and $50 \%$ or $100 \%$ ROBO SAND.

3. Replacement of Natural aggregate with RCA above $30 \%$ is possible to achieve a strength reduction of about $20 \%$ of target mean strength (without any mineral admixture).

\section{REFERENCES}

[1]. Prof. Wakchaure M. R.1, Er. Shaikh A.P.2, Er. Gite B.E.3,(2012), "Effect of Types of Fine Aggregate on Mechanical Properties of Cement Concrete" ,International Journal of Modern Engineering Research (IJMER), Vol.2, Issue.5, Sep-Oct. 2012 pp-3723-3726

[2]. N.K.Deshpande, Dr.S.S.Kulkarni and H.Pachpande,(2012), "Strength Characteristics Of Concrete With Recycled Aggregates And Artificial Sand", International Journal of EngineeringResearch and Applications (IJERA),Vol. 2, Issue 5, September- October 2012, pp.038-042

[3]. M. G. Shaikh, S. A. Daimi,(2011), "Durability studies of concrete made by using artificial sand with dust and natural sand", International Journal of Earth Sciences and Engineering 823ISSN 0974-5904, Volume 04, No 06 SPL, October 2011, pp 823-830

[4]. Pazhani, K., and Jeyaraj, R. 2010. "Study on durability of high performance concrete with industrial wastes.ATI" Applied Technologies \& Innovations, 2(2), 19-28.

[5]. VenuMalagavalli and Rao, P.N. 2010. "High Performance Concrete with GGBFS and ROBO Sand". International Journal of Engineering Science and Technology, 2(10), 5107-5113.

[6]. IS: 383-1970, Indian Standard specification for coarse and fine aggregates from natural sources for concrete.

[7]. IS: 456-2000, Indian standard code of practice for plain and reinforcement concrete, Indian Standard Institution, New Delhi.

[8]. B. B. Patil and P. D. Kumbhar "Strength and Durability Properties of High Performance Concrete incorporating High Reactivity" Powder Technology Vol 2(3), 1099-1104, 2012.
[9]. IS 10262 - 1982 Indian Standard code of practice for recommended guidance for concrete mix design [10]. IS: 383-1970, - Indian Standard code for coarse and fine aggregates from natural sources of concretell.

\section{BIOGRAPHIES}

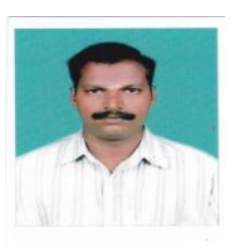

A.Anbarasan is an M.Tech Student at PRIST University, Kumbakonam Campus and his field of interest is in concrete technology.

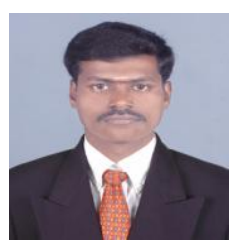

M.Venkatesan, is an Asst. Professor, in PRIST University, Kumbakonam Campus and his field of of interest is in structural analysis, concrete technology 